\title{
Amino Acid Synthesis Inhibition
}

National Cancer Institute

\section{Source}

National Cancer Institute. Amino Acid Synthesis Inhibition. NCI Thesaurus. Code C40624.

Amino Acid Synthesis Inhibition involves interference with, or restraint of, enzymatic formation of organic compounds that contain an amino (-NH2) and a carboxyl (- $\mathrm{COOH})$ group. 